\title{
EVIDENCE FOR SECRETION OF AN ALDOSTERONE-STIMULATING HORMONE BY THE KIDNEY*
}

\author{
By JAMES O. DAVIS, CHARLES C. J. CARPENTER, CARLOS R. AYERS, \\ JOHN E. HOLMAN AND ROBERT C. BAHN WITH THE SURGICAL AS- \\ SISTANCE OF ALFRED CASPER AND THE TECHNICAL ASSISTANCE \\ oF ELEANOR CAVANAUGH \\ (From the Section on Experimental Cardiovascular Disease, Laboratory of Kidney and \\ Electrolyte Metabolism, National Heart Institute and from the Department of \\ Pathological Anatomy, Mayo Clinic, Rochester, Minn.)
}

(Submitted for publication October 17, 1960; accepted December 2, 1960)

In an earlier report (1), it was suggested from cross circulation experiments that a humoral agent provides the immediate stimulus for aldosterone production. It was proposed that this humoral substance be called the aldosterone-stimulating hormone $(\mathrm{ASH})$. The present experiments were designed to determine the locus of secretion of ASH. Specific regions or organs which might be the source of ASH were removed and, subsequently, attempts were made to stimulate aldosterone secretion by bleeding. A positive response to bleeding in the absence of ACTH has been considered as presumptive evidence for secretion of ASH. It is important that studies be conducted in hypophysectomized dogs since bleeding $(2,3)$ stimulates release of ACTH which promotes increased aldosterone secretion. Bleeding was used as a stimulus because it is a simple and effective means of increasing aldosterone production.

Studies were made in normal dogs to establish the magnitude of the response in aldosterone secretion to bleeding. In view of the marked fall in aldosterone secretion following hypophysectomy, the possibility was examined that ASH is secreted by the anterior pituitary. Since a response in aldosterone secretion to acute blood loss was obtained in hypophysectomized dogs, the effects of decapitation and subsequent bleeding were next determined. Finally, the effects of bleeding on aldosterone secretion were observed in hepatectomized-hypophysectomized dogs and in nephrectomized-hypophysectomized animals, and

* This investigation was aided in part by Grant A-1944 from the National Institutes of Health, Bethesda, Md. Preliminary report made during the discussion period at a symposium on aldosterone at the First International Congress of Endocrinology in Copenhagen, Denmark, July 21, 1960. the effects of saline extracts of kidney and of liver on aldosterone secretion have been studied.

\section{METHODS}

The animals were lightly anesthetized with sodium pentobarbital and maintained on a demand pneophore at a pressure of 10 to $15 \mathrm{~cm}$ water. The response to bleeding was measured 1 hour after acute hemorrhage, unless otherwise indicated. Bleeding was accomplished by removal of 250 to $300 \mathrm{ml}$ of blood from the femoral vein of 15 to $20-\mathrm{kg}$ dogs, with one exception; in the last experiment in which the simple hypophysectomized and nephrectomized-hypophysectomized dogs were studied alternately, $16 \mathrm{ml}$ of blood per $\mathrm{kg}$ of body weight was removed. An infusion of norepinephrine (100 $\mu \mathrm{g}$ per $\mathrm{ml}$ ) in 5 per cent glucose was used to support all decapitated and hepatectomized dogs; also, in some of the hypophysectomized and nephrectomized-hypophysectomized dogs, support was necessary. Arterial blood pressure was measured continuously with a Statham strain gauge and a Sanborn recording system. The rate of norepinephrine infusion was varied in an attempt to achieve a constant adrenal blood flow throughout the experiment. Adrenal vein blood was collected by techniques described previously (4).

Hypophysectomy was performed by the oral approach (5). The procedure for decapitation consisted of: 1) placement of loose ligatures around the origin of the left subclavian and brachiocephalic arteries; 2) ligation and section of the cervical muscles at the level of the second cervical vertebra together with isolation of the common carotid arteries, the jugular veins and the vagi; 3) ligation of brachiocephalic and left subclavian arteries; 4) ligation and section of the common carotid arteries, vagi and jugular veins; and 5) removal of the head after cutting the spinal column with an electric saw and bone forceps. In most of the animals, decapitation was complete within 4 minutes after ligation of the blood vessels to the head. The liver was deleted from the circulation by ligation of the hepatic artery near the hilum of the liver, shunting blood from the hepatic portal vein to the femoral vein, and by occluding all outflow from the liver. Outflow occlusion was accomplished by tying a piece of plastic tubing in the inferior vena cava in the 
region of the hepatic venous outflow. The kidneys were extirpated surgically from the dogs.

Saline extracts of the two kidneys from each animal were made by homogenizing the kidney tissue in $300 \mathrm{ml}$ of physiological saline ( 0.85 per cent) in a Waring blender. The homogenate was centrifuged at 8,000 $\mathrm{rpm}$ in a Lourdes model AT centrifuge for 20 minutes. The supernatant was decanted and infused into the femoral vein of the nephrectomized-hypophysectomized assay animal by means of a constant-infusion pump at a rate of 5 to $6 \mathrm{ml}$ per minute. For the liver extracts, an amount of normal dog liver equal to the weight of the kidneys was processed in the same manner as was the kidney.

The concentrations of aldosterone and corticosterone in adrenal vein plasma were measured by the double isotope derivative assay procedure of Kliman and Peterson (6) and the simultaneous secretion rates for the two hormones were determined. The secretion rate of corticosterone rather than of cortisol was measured because of the similar polarity of corticosterone monoacetate and aldosterone diacetate during descending chromatography in the solvent systems used. It has been shown previously (7) that changes in corticosterone secretion are very closely correlated with changes in Porter-Silber chromogen output. To demonstrate the specificity of the
TABLE I

Data on specificity of the double isotope derivative assay procedure for aldosterone in adrenal vein plasma from bled decapitated dogs

\begin{tabular}{cllll}
\hline \multirow{2}{*}{ Dog no. } & \multicolumn{4}{l}{$\mathrm{H}^{3} / \mathrm{C}^{14}$ ratios after each chromatography } \\
\cline { 2 - 5 } & 1st & 2nd & 3rd & 4th \\
\hline 2 & 97.8 & 5.60 & 3.59 & 3.89 \\
3 & 17.8 & 1.09 & 0.54 & 0.83 \\
4 & 56.0 & 1.24 & 0.07 & 0.62 \\
5 & 89.3 & 3.68 & 2.88 & 2.62 \\
8 & 88.8 & 2.40 & 0.92 & 1.05 \\
9 & 14.2 & 0.93 & 0.45 & 0.60 \\
10 & 120.0 & 1.97 & 1.02 & 1.29 \\
& & & & \\
\hline
\end{tabular}

double isotope technique under the present conditions, the $\mathrm{H}^{3} / \mathrm{C}^{14}$ ratios were measured after each of four chromatographies as described elsewhere (1). The results from the study of the $\mathrm{H}^{3} / \mathrm{C}^{14}$ ratios from samples of adrenal vein plasma from 7 of the 9 decapitated dogs which responded to bleeding are presented in Table I. Porter-Silber chromogens were determined by a modification of the method of Peterson, Karrer and Guerra (8).

In the first group of 8 simple hypophysectomized dogs,

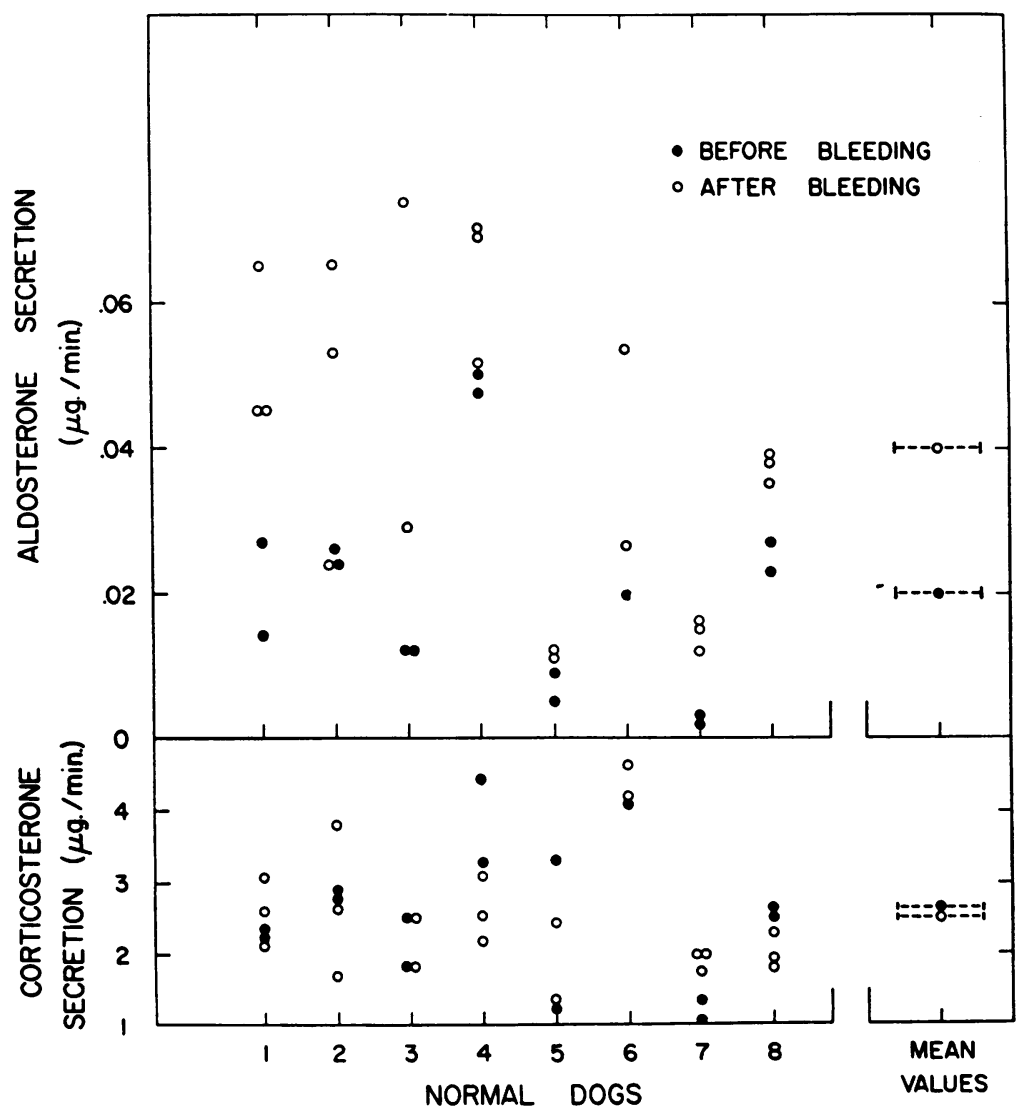

Fig. 1. Aldosterone and corticosterone SECretion before AND AFter BLEEDING OF NORMAL DOGS. 


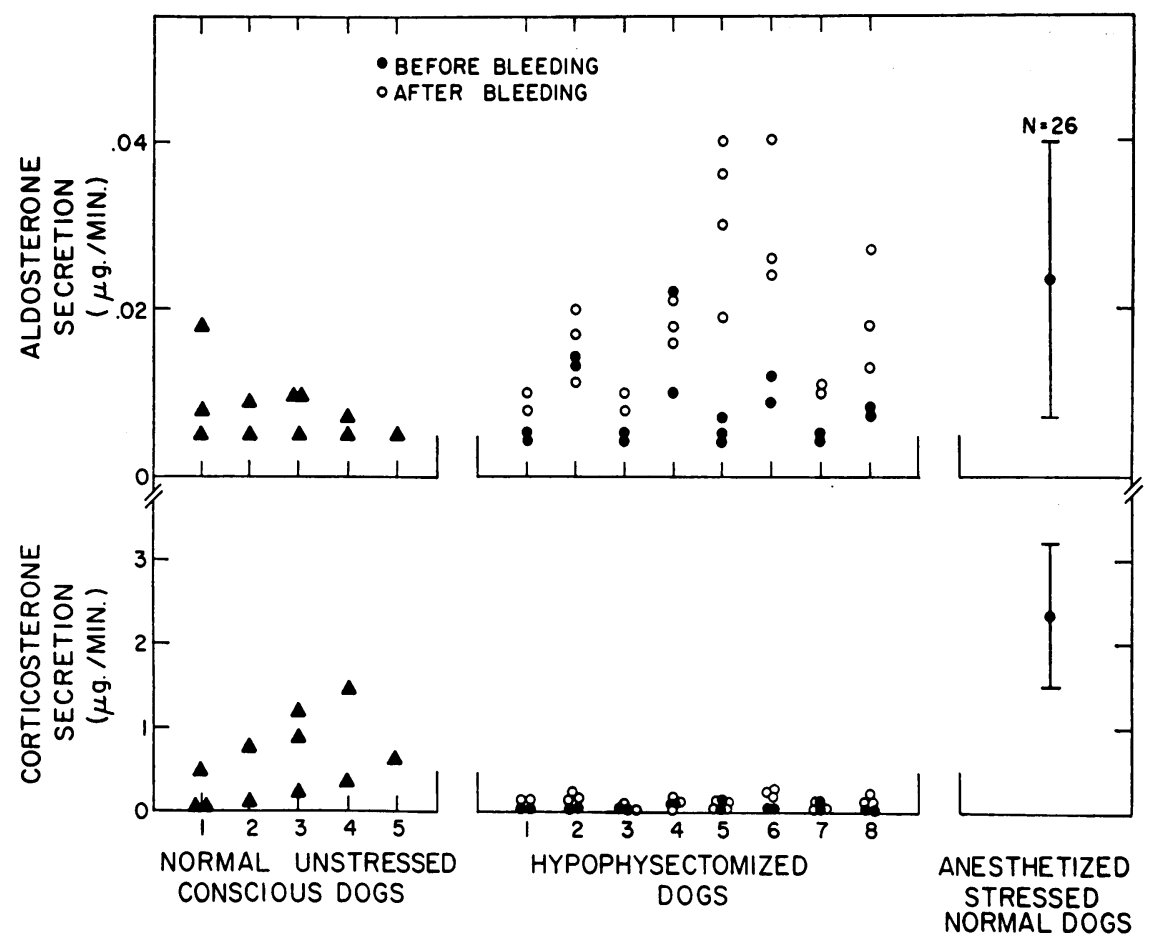

Fig. 2. EFFECTS OF BLEEDING ON ALDOSTERONE AND CORTICOSTERONE SECRETION IN HYPOPHYSECTOMIZED DOGS (CENTER SECTION). For comparison, data are presented from five normal unstressed conscious dogs (on the left) and for the means and standard deviations from anesthetized normal dogs stressed by laparotomy (on the right).

the base of the hypothalamus and any remaining tissue in the sella turcica were sectioned serially to determine the completeness of hypophysectomy.

\section{RESULTS}

Effects of hemorrhage on aldosterone and corticosterone secretion in normal dogs. The response of eight normal dogs to acute blood loss was studied to provide data for comparison with the effects of bleeding in the other experimental groups. The results are presented in Figure 1. The average control value for aldosterone secretion was $0.020 \mu \mathrm{g}$ per minute. One hour after hemorrhage, the rate of aldosterone secretion was significantly increased to $0.040 \mu \mathrm{g}$ per minute $(\mathrm{p}<$ 0.01 ). Corticosterone secretion, which was markedly elevated above the normal basal level (7) during the control period due to the stress of laparotomy, was unchanged following acute hemorrhage. Acute blood loss was frequently accompanied by a slight reduction in arterial pressure.

Effects of bleeding on steroid secretion in hypophysectomized dogs. Eight normal dogs were hypophysectomized and 2 to 4 hours later the response to bleeding was determined (center section of Figure 2). The average control value for aldosterone secretion in the eight hypophysectomized dogs before bleeding was $0.008 \mu \mathrm{g}$ per minute and in four of the animals (Dogs 1, 3, 5 and 7 ), the rate of secretion of aldosterone was below $0.005 \mu \mathrm{g}$ per minute. Following bleeding, the average value for aldosterone secretion in each animal was higher than that during the control period and the mean value for the group was 0.016 $\mu \mathrm{g}$ per minute, which represents a 100 per cent increase $(p<0.02)$. Also, the rates of aldosterone secretion in the bled hypophysectomized dogs were frequently higher than in conscious unstressed normal dogs with a basal output of $\mathrm{ACTH}$ (left section of Figure 2), and in three animals aldosterone secretion was as high or higher than the average value for normal anesthetized dogs subjected to the stress of laparotomy (right section of Figure 2). The control values for corticosterone secretion were very low in the hypophysectomized animals (center section of Figure 
2) and remained low following bleeding in comparison with corticosterone output by the anesthetized stressed animals (right section of Figure $2)$. In individual animals, two or all three values for corticosterone secretion after bleeding were slightly higher than the two control values in five of the dogs (Dogs 1, 2, 3, 6 and 8 of Figure 2); however, the average increase in corticosterone output from 0.059 to $0.109 \mu \mathrm{g}$ per minute was not statistically significant $(\mathrm{p}>0.1)$.

To determine the completeness of hypophysectomy, serial histological sections were made of the base of the hypothalamus and of any tissue remaining in the sella turcica. Hypophysectomy was complete in Dogs 1, 2 and 6 (Figure 2). In Dog 5, a large remnant of pars tuberalis was present and in Dogs 3, 4, 7 and 8 a minute fragment of pars tuberalis remained.

Effects of hemorrhage on aldosterone secretion following decapitation. The results of a typical experiment which illustrate the design used are presented in Figure 3. The initial control values for aldosterone secretion were low as a result of hypophysectomy, and decapitation was without effect. Following bleeding, aldosterone secretion increased 200 per cent, while adrenal blood flow was essentially unchanged.

The results for all ten decapitated dogs before and after bleeding are presented in the center sec- tion of Figure 4. Aldosterone secretion increased in nine of the ten $\operatorname{dogs}$ and the average increase for the group was from 0.007 to $0.022 \mu \mathrm{g}$ per minute $(\mathrm{p}<0.01$ ). In four animals (Dogs 2, 5, 8 and 10), the rates of aldosterone secretion after bleeding were as high or higher than the average value for anesthetized stressed normal dogs (right section of Figure 4). In Dog 5, hypophysectomy was apparently incomplete since the control corticosterone secretion values were considerably higher than the very low rates of corticosterone output by the other dogs. It is of interest that Dog 5 showed the most marked response to bleeding ; the increase in aldosterone secretion was similar to that observed in normal dogs (Figure 1). This result may reflect the importance of sufficient circulating ACTH remaining during the hour following decapitation to effect a marked response to bleeding. The average value for adrenal blood flow was unchanged after bleeding (Figure 5) and both the control and experimental values were essentially the same as the adrenal blood flow of $2.90 \pm \mathrm{a}$ standard deviation of $0.72 \mathrm{ml}$ per minute in anesthetized stressed normal dogs.

Corticosterone secretion was very low before bleeding in all decapitated animals except Dog 5 . Following acute hemorrhage, corticosterone output increased slightly in all but Dog 5, and in Dogs 8 and 10 a substantial increase occurred.

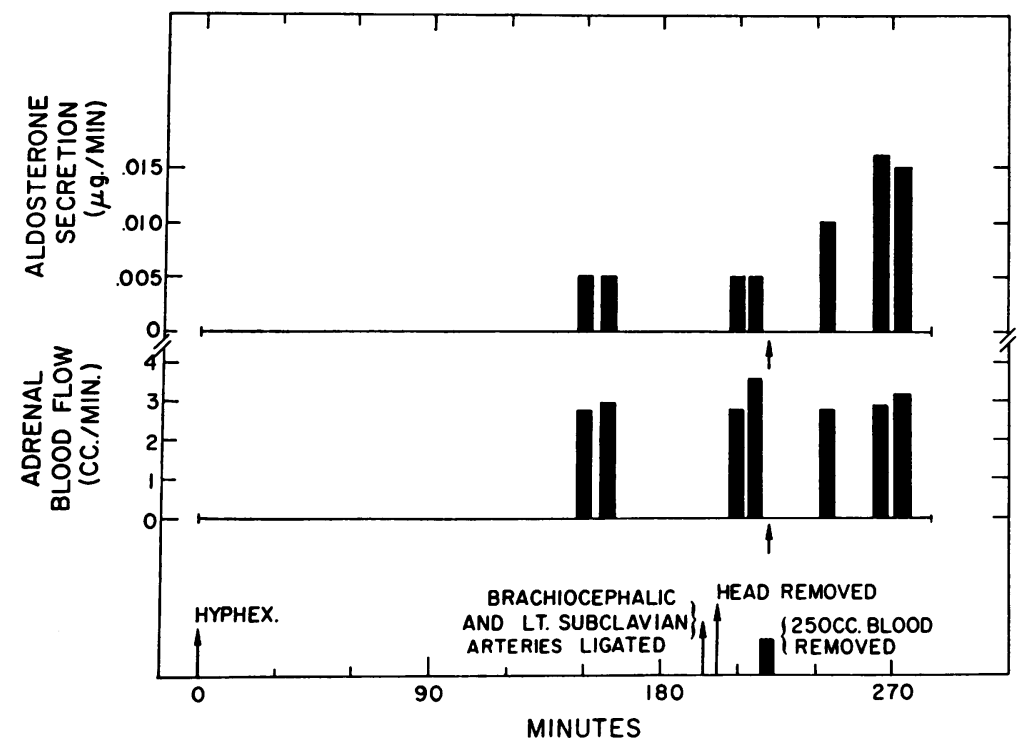

Fig. 3. A typical EXPERIMENT ON THE EFFECTS OF BLEEding on ALDOSTERONE SECRETION AND ADRENAL BLOOD FLOW IN A DECAPITATEd DOG. Hyphex. is the abbreviation for hypophysectomy. 


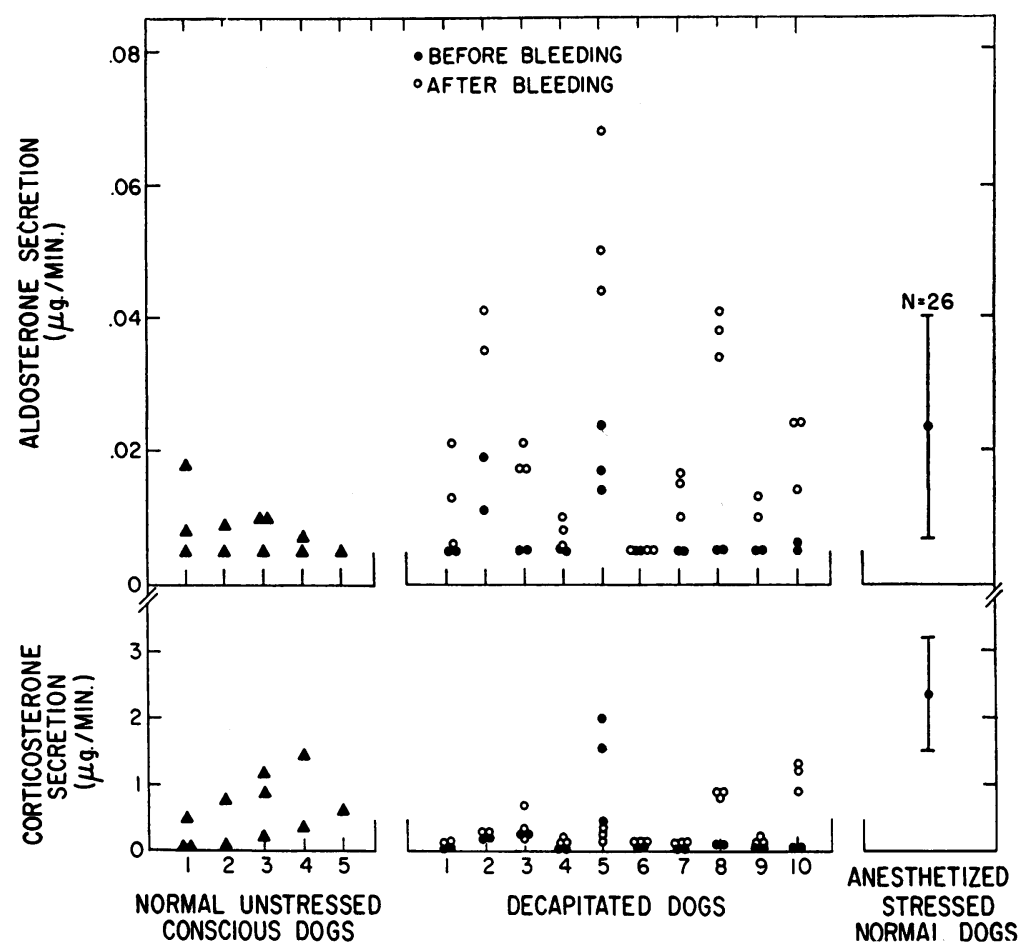

Fig. 4. EFFECTS OF BLEEDING ON STEROID SECRETION IN DECAPITATED DOGS (CEnter section). The same comparative data are presented as in Figure 2 .

However, a statistical analysis of the group, ex- As a control on the effects of decapitation per cluding Dog 5 in which hypophysectomy was in- se on steroid secretion, three additional dogs were complete, yielded an insignificant change $(\mathrm{p}>$ studied immediately after decapitation and 1 hour $0.05)$. later in the absence of bleeding. The results from

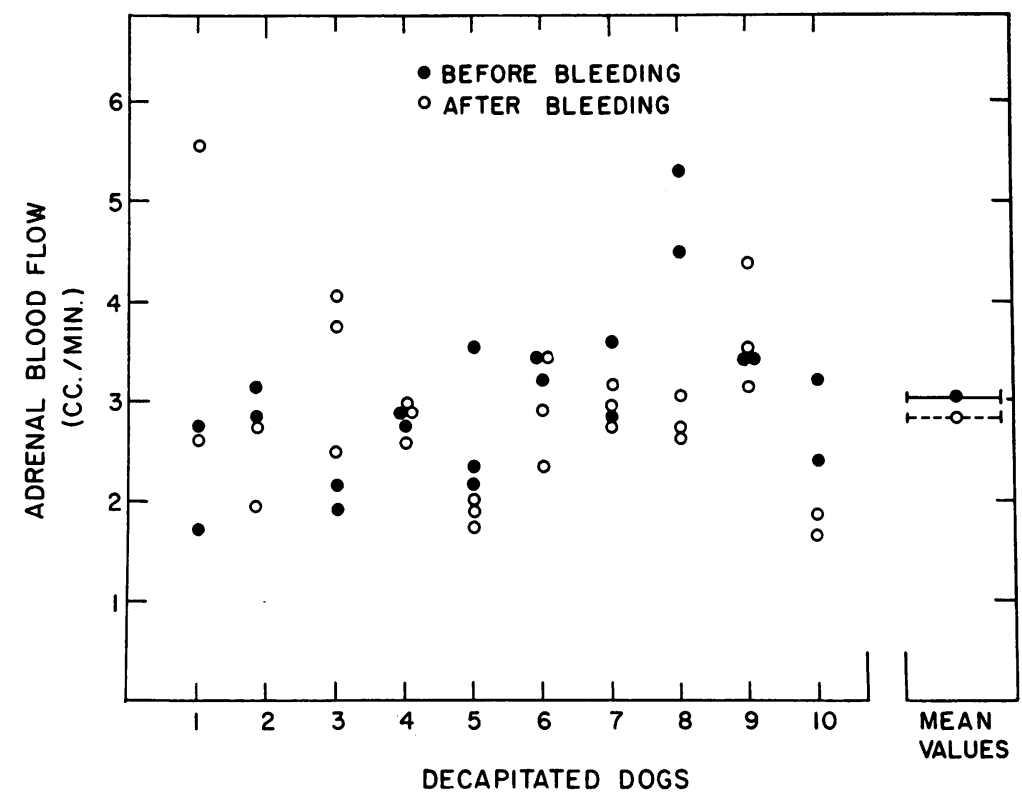

Fig. 5. AdRENAL BLOOD FLOW BEFORE AND AFTER BLEEDING FOR THE SAME COLLECTION PERIODS ON THE TEN DECAPITATEd dOGS OF Figure 4. 


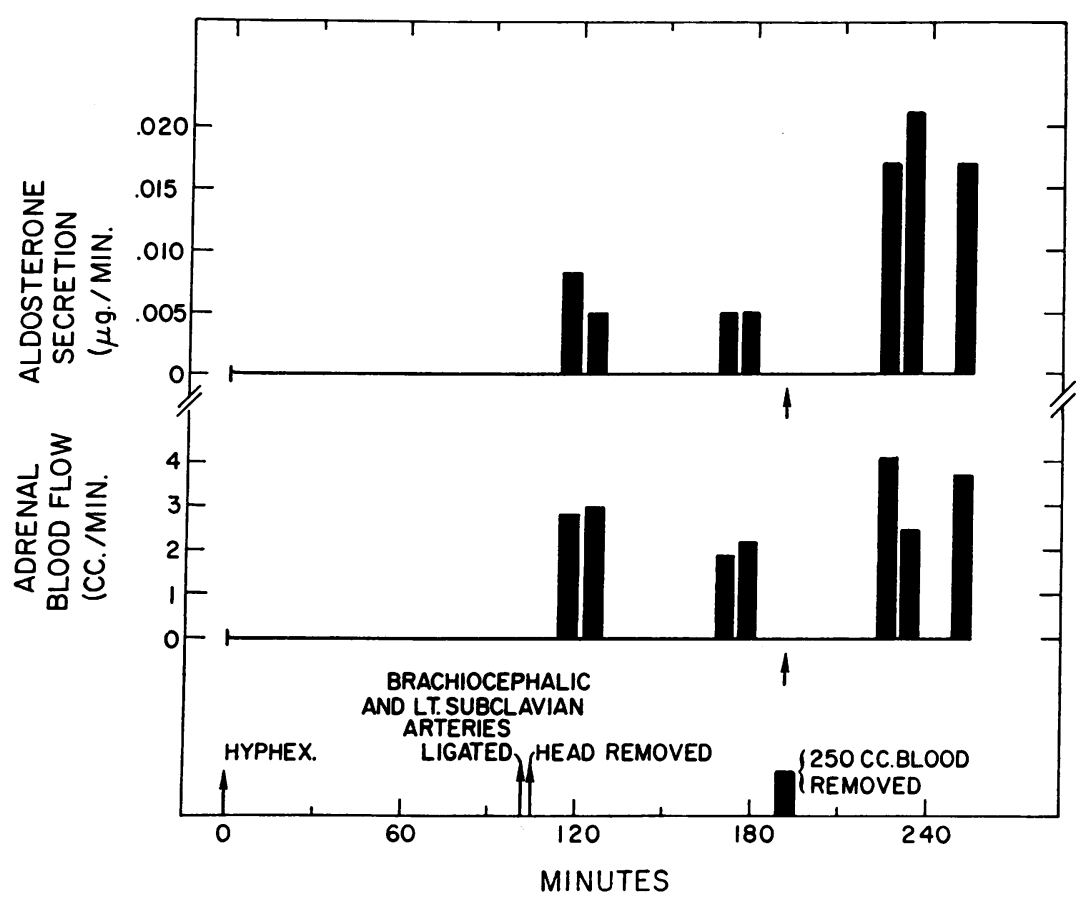

Fig. 6. Failure of ALdosterone SECretion to INCREASE 1 hOUR AFTER DECapitation in the ABSENCE of bleEding. Subsequently, acute blood loss effected the usual elevation in aldosterone output.

a typical experiment are presented in Figure 6; at the end of the 1 hour control period, aldosterone secretion was at the low posthypophysectomy level. Also, in the other two dogs, aldosterone output was low at the end of the control period. In the first animal studied (Figure 6), after the control period the typical response in aldosterone secretion to bleeding occurred. Corticosterone output was unchanged in two dogs and increased slightly in the other animal. The results show, therefore, that decapitation per se was without effect on aldosterone secretion. It is concluded that ASH is extracranial in origin.

Effects of bleeding on steroid secretion in hepatectomized-hypophysectomized animals. The liver and the kidney were considered as the two most likely extracranial sites for secretion of ASH. These two organs consist of large masses of highly differentiated parenchymatous tissue and both organs are very important in the pathogenesis of ascites (9). The possibility of secretion of ASH by the liver was examined first. The anterior pituitary was removed to exclude the effects of an increase in ACTH secondary to bleeding since $\mathrm{ACTH}$ release might obscure the response in aldosterone secretion to ASH.
The results from bleeding of 12 hepatectomizedhypophysectomized dogs are presented in the center section of Figure 7. Failure of Dogs 1-4 to respond to bleeding is probably attributable to the deterioration of the animals; it was difficult to keep these first four animals alive after hypophysectomy, hepatectomy and acute hemorrhage. With experience, hepatectomy was performed more quickly and arterial pressure was sustained more effectively by careful regulation of the norepinephrine and glucose infusion. In contrast to Dogs $1-4$, a definite increase in aldosterone secretion followed bleeding in Dogs 5-11. These increases in aldosterone secretion in Dogs 5-11 were not associated with increases in adrenal blood flow. Of considerable importance is the level of aldosterone secretion observed before bleeding in the hepatectomized-hypophysectomized dogs; the mean value for the group (exclusive of Dog 12 in which hypophysectomy was apparently incomplete) was $0.012 \mu \mathrm{g}$ per minute. This value is in marked contrast to the very low rates of aldosterone secretion observed in the absence of the kidneys (Figure 8). The difference between the rate of aldosterone secretion of $0.012 \mu \mathrm{g}$ per minute before bleeding in the hepatectomized-hypophysec- 


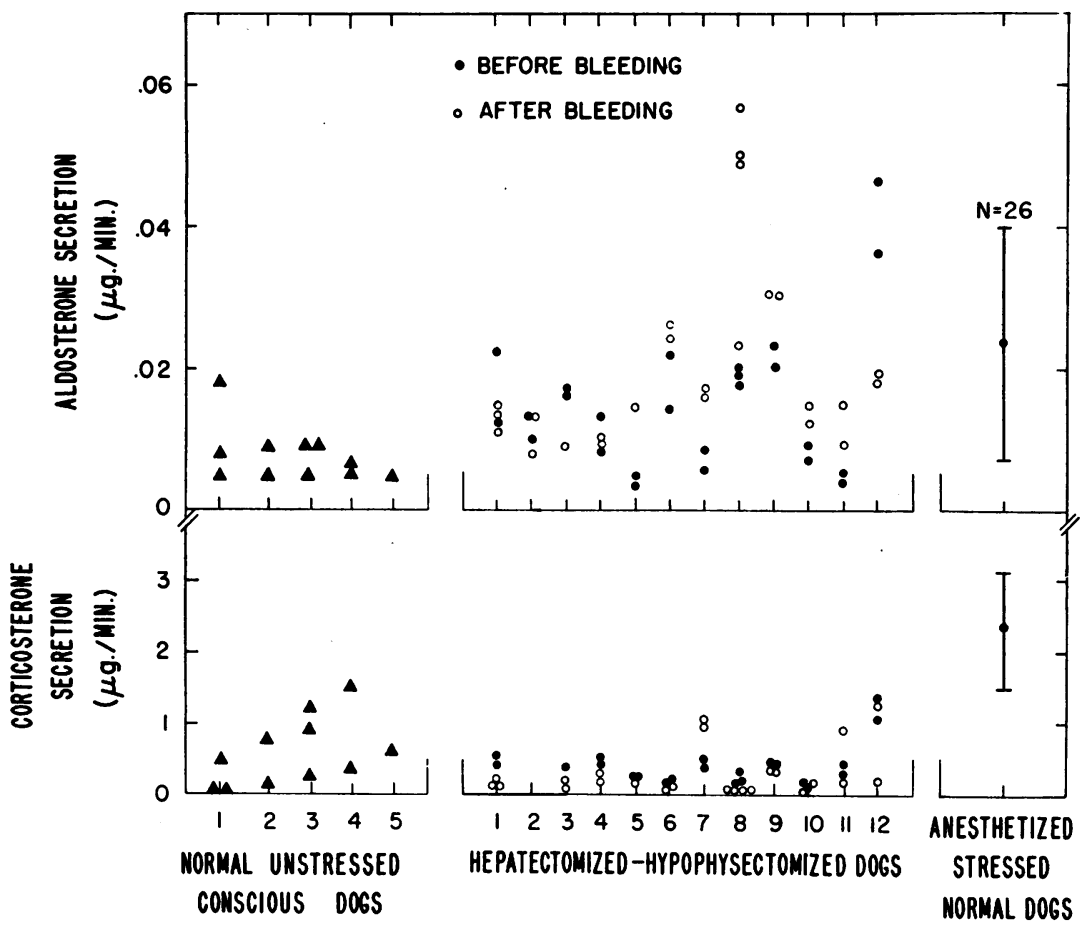

Fig. 7. EFFECTS OF HEMORRHAGE ON STEROID SECRETION IN HEPATECTOMIZEDHYPOPHYSECTOMIZED DOGS (CENTER SECTION). The comparative data of Figure 2 are presented on the left and on the right.

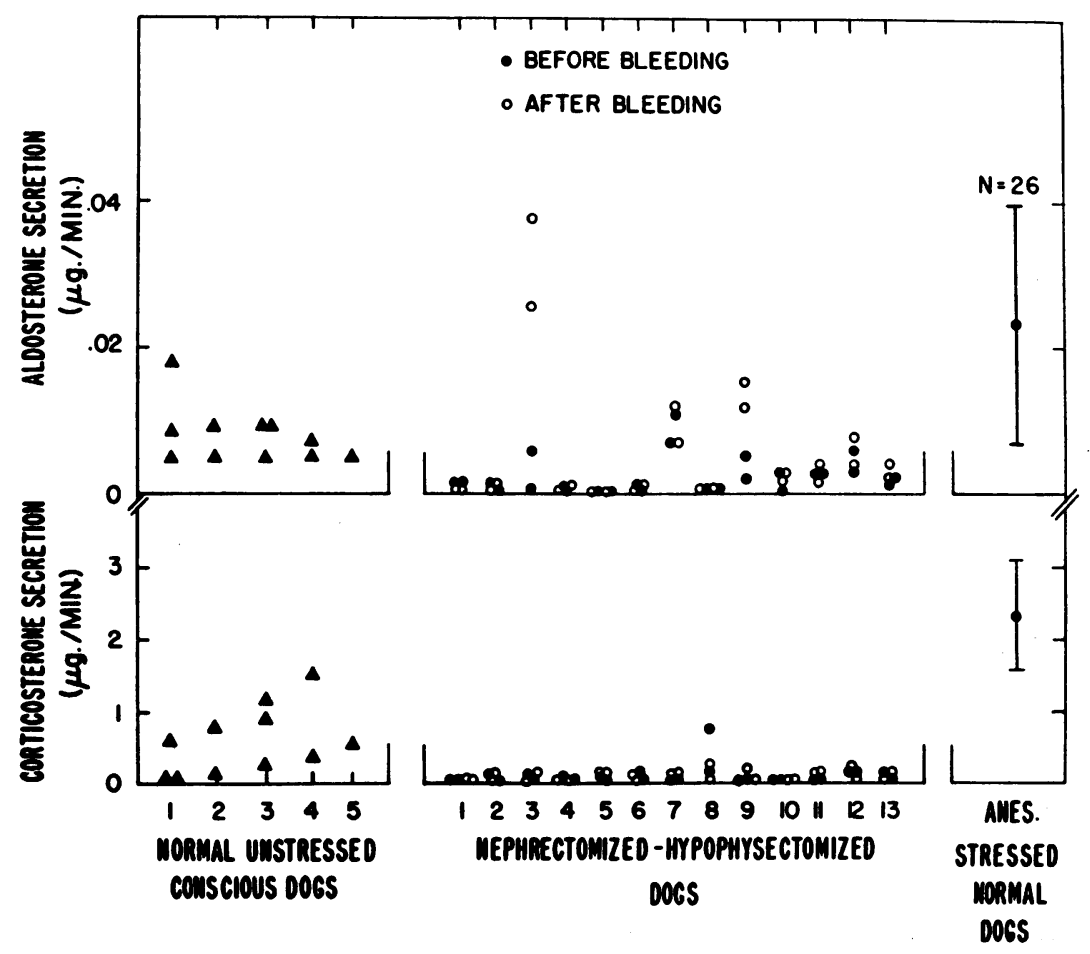

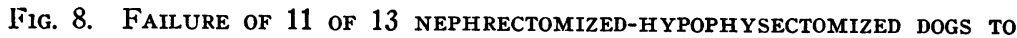
RESPOND TO ACUTE BLOOD LOSS BY AN ELEVATION IN ALDOSTERONE SECRETION. The same comparative data are presented as in Figure 2. 
tomized dogs and that of $0.003 \mu \mathrm{g}$ per minute in the 13 nephrectomized-hypophysectomized dogs of Figure 8 is highly significant $(\mathrm{p}<0.001)$. The data indicate that a substantial amount of ASH is secreted by a source other than the liver.

Corticosterone secretion was low before bleeding and failed to change significantly $(p>0.9)$.

Evidence for secretion of an aldosterone-stimulating hormone by the kidney. In the first part of this experiment, the response to bleeding was studied in 13 nephrectomized-hypophysectomized dogs; the spleen was also removed in Dogs 1-5 of Figure 8. The experimental design and typical findings are presented in Figure 9 and the results for all 13 animals are plotted in Figure 8. Aldosterone secretion was very low before bleeding and 11 of the 13 dogs failed to respond to acute blood loss. However, in Dogs 3 and 9, aldosterone secretion was higher after than before bleeding. In samples from both animals, the radiochemical purity of the final radioactive area on the chromatogram was demonstrated; the $\mathrm{H}^{3} / \mathrm{C}^{14}$ ratios were constant after three chromatographies. Also, repeat analyses of another set of samples from each dog showed the same apparent increase that was observed from the first group of analyses. The control values for corticosterone output before bleeding were also very low (0.05 $\mu \mathrm{g}$ per minute) and no change occurred after acute hemorrhage ( $p>$ 0.9 ). Adrenal blood flow was essentially the same before and after bleeding ( $p>0.1)$.

Because Dogs 3 and 9 of Figure 8 appeared to show a response to bleeding, another group of animals was studied (Figure 10). Observations on the effects of bleeding in eight simple hypophysectomized dogs were made alternately with studies in nine nephrectomized-hypophysectomized animals. The numbers show the consecutive order in which the animals were studied. Dogs 1 and 2 of Figure 10 are Dogs 12 and 13 of Figure 8. The other 15 dogs of Figure 10 represent a new group of animals.

Aldoesterone secretion increased slightly in every simple hypophysectomized dog (Figure 10) and the change was statistically significant for the group $(p<0.02)$. In contrast, only one of the group of nine nephrectomized-hypophysectomized dogs showed an increase in aldosterone secretion

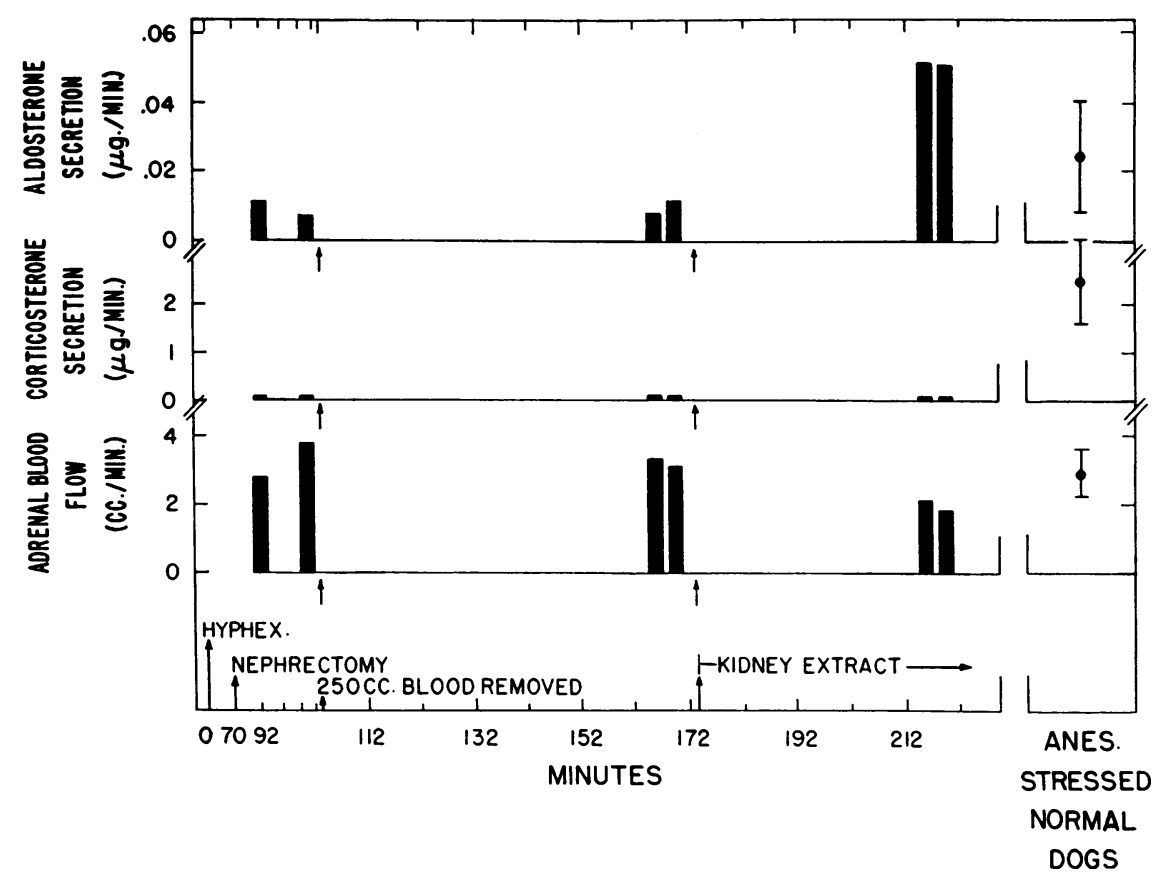

Fig. 9. A typical experiment on the efFECts of BleEding on STERoid SECRETION IN A NEPHRECTOMIZED-HYPOPHYSECTOMIZED DOG AND THE SUBSEQUENT RESPONSE TO A CELl-Free Saline extract of the animal's own kidneys. For comparison, the mean values and standard deviations for 26 anesthetized normal dogs stressed by laparotomy are presented on the right. 

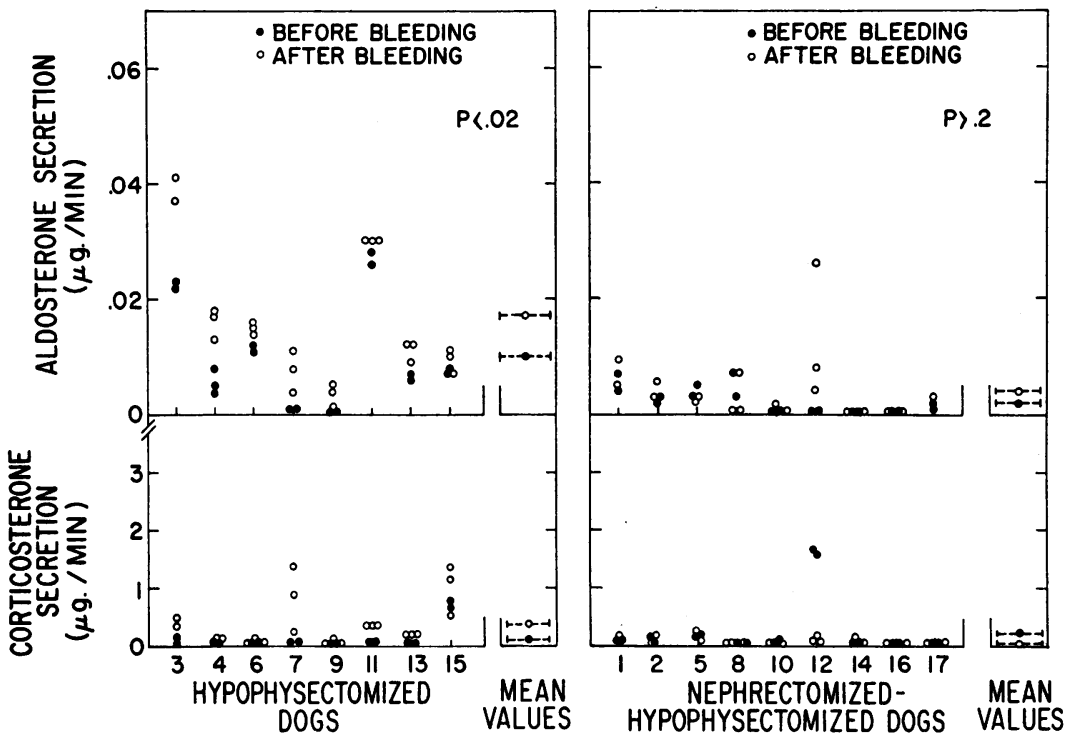

Fig. 10. Comparative efFects of ACUte Blood losS (16 ML PER KG) on STEROID SECRETION IN TWO GROUPS OF DOGS. The animals were studied in consecutive numerical order. A definite response in aldosterone secretion occurred in the hypophysectomized dogs (left section), but only one of the nephrectomized-hypophysectomized animals showed a response (right section).

after bleeding $(p>0.2)$. Also, the initial control values before bleeding appeared to be lower in the nine nephrectomized-hypophysectomized dogs than in the eight simple hypophysectomized animals of Figure 10, and no tritium was present in samples from Dogs 14 and 16. Comparison of

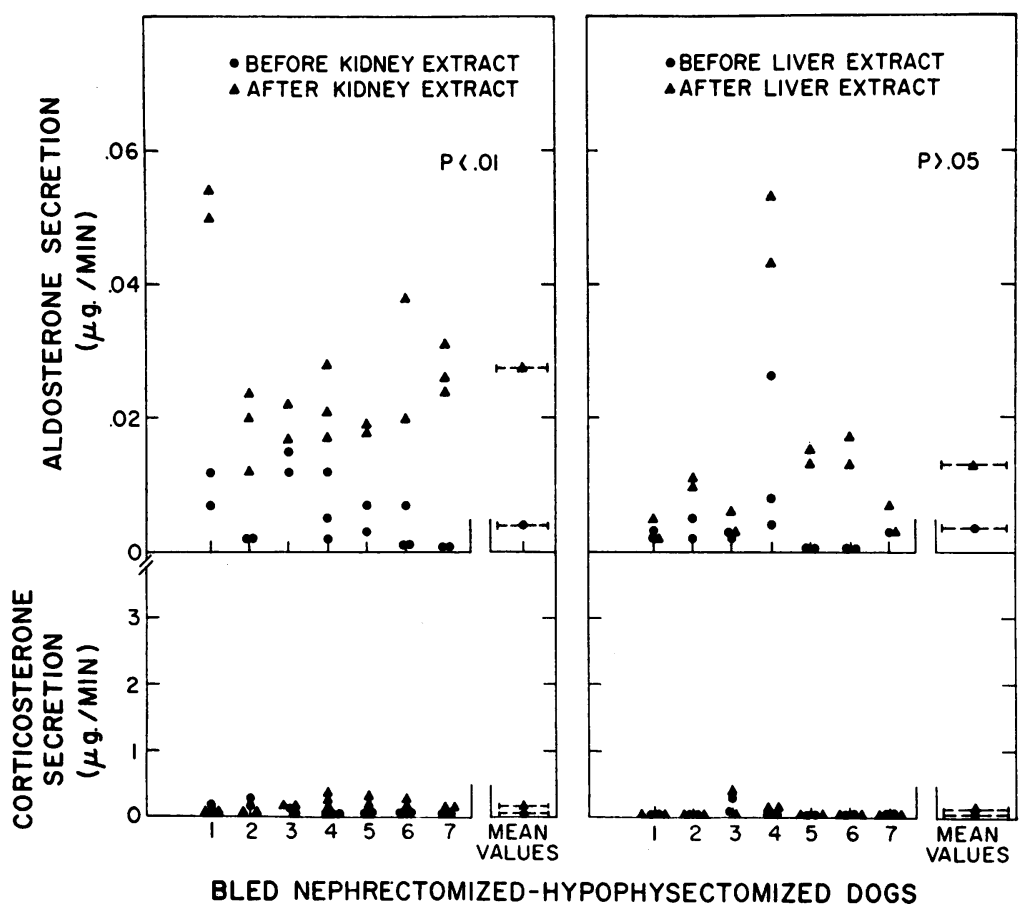

Fig. 11. EFFECTS OF SALINE EXTRACTS OF KIDNEY (LEFT SECTION) AND OF LIVER (RIGHT SECTION) ON STEROID SECRETION IN BLED NEPHRECTOMIZEDHYPOPHYSECTOMIZED DOGS, 
the control values before bleeding in all 16 simple hypophysectomized dogs (Figures 2 and 10) with all 20 nephrectomized-hypophysectomized animals (Figures 8 and 10) showed mean values of 0.009 and $0.0045 \mu \mathrm{g}$ per minute, respectively, a difference which was highly significant $(p<0.001)$.

Corticosterone secretion in the simple hypophysectomized dogs (Figure 10) was low before bleeding and increased slightly after acute hemorrhage in five of the eight dogs; also, the increase for the group was statistically significant $(p<$ 0.01 ). In the nephrectomized-hypophysectomized dogs (Figure 10), corticosterone secretion was unchanged $(p>0.9)$.

The response to saline extracts of the kidney in 7 of the 20 nephrectomized-hypophysectomized animals was studied (Figure 11). Aldosterone secretion increased in every animal and the increase for the group was from 0.004 to $0.028 \mu \mathrm{g}$ per minute, a sevenfold increase which was highly significant $(p<0.01)$. Corticosterone secretion was unaffected by the kidney extracts $(p>0.1)$. Porter-Silber chromogens were $0.08 \mu \mathrm{g}$ per minute before and $0.05 \mu \mathrm{g}$ per minute after the infusion of the kidney extracts $(p>0.9)$. Also, adrenal blood flow was unchanged $(p>0.9)$. No consistent effect on arterial blood pressure was observed.

To obtain evidence on the specificity of the response to renal extracts, saline extracts of liver were studied under circumstances indentical with those used for the kidney extracts. An increase in aldosterone secretion occurred in only four of the seven dogs and the change for the group was not statistically significant $(p>0.05)$ (Figure 11). The liver extracts had no effect on corticosterone secretion. The data suggest that the response to kidney extracts represents a specific effect.

\section{DISCUSSION}

Substantial evidence has accumulated to demonstrate that the immediate stimulus to aldosterone production is humoral. Indirect evidence was obtained from experiments in which the transplanted adrenal was stimulated to secrete increased amounts of aldosterone by acute blood loss (3), chronic thoracic caval constriction (3) and $\mathrm{Na}$ depletion (10). Direct evidence was provided by cross circulation of blood from hyperaldosteronemic donors with thoracic caval constriction through normal isolated adrenals with a resultant increase in aldosterone secretion by the isolated adrenals (1). Also, concurrent independent observations by Denton, Goding and Wright (11) showed that another stimulus, namely $\mathrm{Na}$ depletion, gave rise to a circulating aldosterone-stimulating factor in sheep.

In the present study, several sites have been examined as the possible locus for secretion of the aldosterone-stimulating hormone released secondary to acute blood loss. The response in aldosterone secretion to bleeding in hypophysectomized dogs demonstrated an extrapituitary origin of ASH. This result agrees with the almost identical response to bleeding of hypophysectomized dogs observed by Mulrow and Ganong (2). Also, the finding of hypersecretion of aldosterone in completely hypophysectomized dogs with thoracic caval constriction indicates an extrapituitary origin for $\operatorname{ASH}(7)$.

In a previous study (12), it was demonstrated that midbrain transection failed to result in decreased aldosterone secretion, and subsequent elevation in aldosterone secretion occurred in response to acute blood loss. Also, destruction of the pineal gland and associated structures was without effect on urinary aldosterone and $\mathrm{Na}$ excretion, and subsequent thoracic caval constriction resulted in hypersecretion of aldosterone (9). These findings suggest that ASH originates either from the lower brain stem or from an extracranial organ.

To discriminate between these two possible sources of ASH, dogs were decapitated and bled. A 200 per cent increase in aldosterone secretion occurred following acute hemorrhage. The average increase in aldosterone secretion from 0.007 to $0.022 \mu \mathrm{g}$ per minute (an increment of $0.015 \mu \mathrm{g}$ per minute) was almost as great as the elevation of $0.020 \mu \mathrm{g}$ per minute in normal dogs in response to acute hemorrhage. Since ACTH and ASH are both released in response to acute hemorrhage, a smaller response in aldosterone output would be expected in the absence of the anterior pituitary. The control experiment in which observations were made 1 hour after decapitation but without bleeding demonstrates that the increase in aldosterone production resulted in response to bleeding in the decapitated dogs and was not secondary to decapitation per se or to trauma associated 
with removal of the heal. Also, the control observations show that the increase in aldosterone production following decapitation and bleeding is not the result of loss of an inhibitory factor. If Dog 5 of Figure 4 is excluded because of an incomplete hypophysectomy, the response in aldosterone secretion to acute hemorrhage in the nine decapitated dogs is almost identical with the response of the simple hypophysectomized animals. This finding gives no indication that more ASH was released in the presence than in the absence of the brain. At this point in our studies, it was concluded that ASH is secreted by an extracranial organ.

We reasoned that the liver and kidney are the two most likely extracranial sites for secretion of ASH. Hepatectomy of hypophysectomized dogs and subsequent bleeding provided evidence for an extrahepatic source of ASH. The initial control values for aldosterone secretion before bleeding in hepatectomized-hypophysectomized dogs were considerably higher than in nephrectomized-hypophysectomized animals and a substantial elevation in aldosterone secretion occurred following acute blood loss in seven hepatectomized-hypophysectomized dogs.

The first evidence for secretion of ASH by the kidney was the failure of nephrectomized-hypophysectomized animals to respond to acute hemorrhage by an increase in aldosterone production. Also, the control values for aldosterone secretion before bleeding in nephrectomized-hypophysectomized animals were significantly less than those in hypophysectomized dogs. Direct evidence for a potent stimulator of aldosterone secretion in kidney tissue was demonstrated by the striking consistent increase in aldosterone production during the infusion of saline extracts of kidney, but no effect on corticosterone secretion or Porter-Silber chromogen output occurred. However, in more recent unpublished studies of fractions of crude kidney extracts, certain fractions do stimulate corticosterone production. During the discussion of the author's lecture on the present data at the Laurentian Hormone Conference for 1960, Mulrow and Ganong (13) reported that aldosterone secretion failed to increase following bleeding in four of six nephrectomized-hypophysectomized dogs and intravenous injection of kidney extracts augmented aldosterone production.
It is of interest that corticosterone secretion was occasionally, but not consistently, increased slightly following bleeding in the simple hypophysectomized dogs and in the decapitated dogs. This finding may reflect an influence of ASH on corticosterone secretion in some experiments. The occasional increase in corticosterone secretion after bleeding in the presence of the kidney is in contrast to the consistent failure of a response in corticosterone production to bleeding in the nephrectomized-hypophysectomized dogs of Figures 8 and 10 in which high p values were obtained.

The present results provide evidence for secretion of an aldosterone-stimulating hormone by the kidney in response to acute blood loss. Is this hormone the same substance present in experimental secondary hyperaldosteronism (1)? Observations on the effect of nephrectomy in ten hypophysectomized dogs with thoracic caval constriction have demonstrated a marked drop in aldosterone secretion (unpublished data). This finding and the present data are consistent with the view that a common aldosterone-stimulating hormone, $\mathrm{ASH}$, provides the immediate stimulus to aldosterone production following acute hemorrhage and in experimental secondary hyperaldosteronism.

What is the nature of ASH? One possibility is that $\mathrm{ASH}$ is renin or renin-like in nature. The hypothesis that the renin-hypertensin system is concerned in the physiological control of aldosterone secretion and that a feedback mechanism to the kidney exists has been clearly outlined by Gross (14). There are many experimental findings on the relationship of the adrenal cortex, aldosterone, DCA, salt and renal hypertension to one another and these have been outlined by Tobian (15). Recent evidence has been provided to demonstrate that hypertensin II augments aldosterone secretion. Genest, Koiw, Nowaczynski and Sandor (16) found that hypertensin II increased urinary aldosterone excretion in man, and Laragh, Angers, Kelly and Lieberman (17) demonstrated an increase in the rate of aldosterone secretion during infusion of hypertensin II to humans. Also, the intravenous infusion of hypertensin II increased aldosterone production in nephrectomized-hypophysectomized dogs (18). Finally, there are case reports (19-21) in man in which unilateral renal disease such as renal artery oc- 
clusion was associated with hypertension and hyperaldosteronism. There is, therefore, some indirect evidence for a causal relation of the reninhypertensin system to aldosterone secretion, but the precise relationship and its physiological significance remain to be defined. The more recent finding of a normal rate of aldosterone secretion in dogs with experimental renal hypertension (personal observations) constitutes evidence against the renin-hypertensin system in the control of aldosterone secretion. Another possibility which must be considered is that renin and $\mathrm{ASH}$ are distinctly different substances in the same or in different biochemical pathways in the kidney.

Similarly, the nature of the stimulus which releases ASH from the kidney is unknown. The explanation proposed by Tobian (15) that a decreased volume or pressure in the afferent arterioles of the kidney might lead to release of renin by the juxtaglomerular cells deserves consideration as the mechanism for release of ASH. Following hemorrhage, there is a decrease in total blood volume and, frequently, a fall in arterial pressure results. In dogs with thoracic caval constriction, a high venous pressure below the constricting ligature is essential for initiation of the sequence of changes leading to hyperaldosteronism (22). Following caval constriction, the high hydrostatic pressure leads to loss of fluid and electrolytes from the blood stream and to an acute decrease in plasma volume (22). The reduced plasma volume is restored to normal by retention of salt and water in dogs with caval constriction (23) or increased above normal in experimental right heart failure (24). A plausible working hypothesis is that a decreased volume or pressure occurs in a specific region of the kidney and that this local change leads to release of ASH.

\section{SUMMARY AND CONCLUSIONS}

Experiments were undertaken to determine the locus of secretion of the aldosterone-stimulating hormone which provides the immediate stimulus to aldosterone production. In the absence of $\mathrm{ACTH}$, an increase in aldosterone secretion secondary to acute blood loss was considered as presumptive evidence for secretion of ASH. In a series of successive ablation experiments, removal of the anterior pituitary, the head, or the liver was followed by an increase in aldosterone secretion in response to acute hemorrhage. Following extirpation of the kidney and anterior pituitary, acute blood loss failed to effect a significant change in aldosterone secretion and the basal rate of aldosterone production before bleeding was markedly reduced. Intravenous infusion of saline extracts of kidney into nephrectomized-hypophysectomized dogs resulted in a marked increase in aldosterone secretion, whereas saline extracts of liver studied similarly failed to produce a significant response. The data provide evidence for the renal origin of an aldosterone-stimulating hormone.

\section{REFERENCES}

1. Yankopoulos, N. A., Davis, J. O., Kliman, B., and Peterson, R. E. Evidence that a humoral agent stimulates the adrenal cortex to secrete aldosterone in experimental secondary hyperaldosteronism. J. clin. Invest. 1959, 38, 1278.

2. Mulrow, P. J., and Ganong, W. F. Aldosterone secretion following hemorrhage in hypophysectomized dogs. Fed. Proc. 1960, 19, 152.

3. Carpenter, C. C. J., Davis, J. O., Holman, J. E., Ayers, C. R., and Bahn, R. C. Studies on the response of the transplanted kidney and the transplanted adrenal gland to thoracic inferior vena caval constriction. J. clin. Invest. 1961, 40, 196.

4. Davis, J. O., Pechet, M. M., Ball, W. C., Jr., and Goodkind, M. J. Increased aldosterone secretion in dogs with right-sided congestive heart failure and in dogs with thoracic inferior vena cava constriction. J. clin. Invest. 1957, 36, 689.

5. Davis, J. O., Bahn, R. C., Goodkind, M. J., and Ball, W. C., Jr. Aldosterone excretion in urine from hypophysectomized dogs with thoracic inferior vena cava constriction. Amer. J. Physiol. 1958, $191,329$.

6. Kliman, B., and Peterson, R. E. Double isotope derivative assay of aldosterone in biological extracts. J. biol. Chem. 1960, 235, 1639.

7. Davis, J. O., Carpenter, C. C. J., Ayers, C. R., and Bahn, R. C. Relation of anterior pituitary function to aldosterone and corticosterone secretion in conscious dogs. Amer. J. Physiol. 1960, 199, 212.

8. Peterson, R. E., and Karrer, A., and Guerra, S. L. Evaluation of Silber-Porter procedure for determination of plasma hydrocortisone. Analyt. Chem. 1957, 29, 144.

9. Davis, J. O. Mechanisms of salt and water retention in congestive heart failure. The importance of aldosterone. Amer. J. Med. 1960, 29, 486.

10. McDonald, I. R., Goding, J. R., and Wright, R. D. Transplantation of the adrenal gland of the sheep to provide access to its blood supply. Aust. J. exp. Biol. med. Sci. 1958, 36, 83. 
11. Denton, D. A., Goding, J. R., and Wright, R. D. Control of adrenal secretion of electrolyte-active steroids. Adrenal stimulation by cross-circulation experiments in conscious sheep. Brit. med. J. 1959, 2, 522.

12. Davis, J. O., Anderson, E., Carpenter, C. C. J., Ayers, C. R., Haymaker, W., and Spence, W. T. Effects of midbrain transection and subsequent bleeding on aldosterone and corticosterone secretion. Amer. J. Physiol. In press.

13. Mulrow, P. J., and Ganong, W. F. Discussion of : Davis, J. O. Mechanisms regulating the secretion and metabolism of aldosterone in experimental secondary hyperaldosteronism. Recent Progr. Hormone Res. 1961. In press.

14. Gross, F. Renin und Hypertensin, physiologische oder pathologische Wirkstoffe. Klin. Wschr. 1958, 36, 693.

15. Tobian, L. Interrelationship of electrolytes, juxtaglomerular cells and hypertension. Physiol. Rev. 1960, 40, 280.

16. Genest, J. E., Koiw, E., Nowaczynski, W., and Sandor, T. Study of urinary adrenocortical hormones in human arterial hypertension in Abstracts of the First International Congress of Endocrinology. Copenhagen, 1960, p. 173.

17. Laragh, J. H., Angers, M., Kelly, W. G., and Lieberman, S. Hypotensive agents and pressor substances. The effect of epinephrine, norepinephrine, angiotensin II, and others on the secretory rate of aldosterone in man. J. Amer. med. Ass. 1960, 174, 234.

18. Davis, J. O. Mechanisms regulating the secretion and metabolism of aldosterone in experimental secondary hyperaldosteronism. Recent Progr. Hormone Res. 1961. In press.

19. Hoet, J. J. Discussion in An International Symposium on Aldosterone, A. F. Muller and C. M. O'Connor, Eds. London, J. and A. Churchill, 1958, p. 216.

20. Stanbury, S. W. Discussion in An International Symposium on Aldosterone, A. F. Muller and C. M. O'Connor, Eds. London, J. and A. Churchill, 1958, p. 221.

21. Laidlaw, J. C., Yendt, E. R., and Gornall, A. G. Hypertension caused by renal artery occlusion simulating primary aldosteronism. Metabolism 1960, 9, 612.

22. Davis, J. O., Kliman, B., Yankopoulos, N. A., and Peterson, R. E. Increased aldosterone secretion following acute constriction of the inferior vena cava. J. clin. Invest. 1958, 37, 1783.

23. Davis, J. O., and Howell, D. S. Mechanisms of fluid and electrolyte retention in experimental preparations in dogs. II. With thoracic inferior vena cava constriction. Circulat. Res. 1953, 1, 171.

24. Davis, J. O., Hyatt, R. E., and Howell, D. S. Rightsided congestive heart failure in dogs produced by controlled progressive constriction of the pulmonary artery. Circulat. Res. 1955, 3, 252. 